Research Article

\title{
Spatiotemporal Evolution of Atmospheric Ammonia Columns over the Indo-Gangetic Plain by Exploiting Satellite Observations
}

\author{
Aimon Tanvir, ${ }^{1}$ Muhammad Fahim Khokhar ${ }^{D},{ }^{1}$ Zeeshan Javed $\left(D,{ }^{2}\right.$ Osama Sandhu, ${ }^{1}$ \\ Tehreem Mustansar, ${ }^{1}$ and Asadullah Shoaib ${ }^{1}$ \\ ${ }^{1}$ Institute of Environmental Sciences and Engineering, National University of Sciences and Technology, \\ Islamabad 44000, Pakistan \\ ${ }^{2}$ School of Earth and Space Sciences, University of Science and Technology of China, Hefei 230026, China \\ Correspondence should be addressed to Muhammad Fahim Khokhar; fahim.khokhar@iese.nust.edu.pk and Zeeshan Javed; \\ zeeshan@mail.ustc.edu.cn
}

Received 21 March 2019; Accepted 13 June 2019; Published 1 July 2019

Guest Editor: Salman Tariq

Copyright (C) 2019 Aimon Tanvir et al. This is an open access article distributed under the Creative Commons Attribution License, which permits unrestricted use, distribution, and reproduction in any medium, provided the original work is properly cited.

\begin{abstract}
This study was aimed at presenting a continuous and spatially coherent picture of ammonia $\left(\mathrm{NH}_{3}\right)$ distribution over the IndoGangetic Plain (IGP) by exploiting satellite observations. Atmospheric columns of ammonia were mapped over South Asia by using TES observations on board NASA's Aura satellite. Monthly mean data were used to identify emission sources of atmospheric ammonia across the South Asian region. Data were analysed to explore temporal trends, seasonal cycles, and hot spots of atmospheric ammonia within the study area. The results show that the IGP region has the most ammonia concentrations in terms of column densities, and hence this region has been identified as an ammonia hot spot. This is attributed majorly to extensive agricultural activity. Time series showed a slight increase in ammonia column densities over the study area from 2004 to 2011. Different seasonal cycles were identified across the IGP region with maximum $\mathrm{NH}_{3}$ columns observed during the month of July in most of the subregions. Seasonality in an ammonia column is driven by different cropping patterns and meteorological conditions in the IGP subregions. Global emission inventories of atmospheric ammonia were largely overestimating as compared to satellite observations.
\end{abstract}

\section{Introduction}

Ammonia $\left(\mathrm{NH}_{3}\right)$ is a highly reactive and soluble alkaline gas [1] in the atmosphere having a short lifetime of 1 day $[2,3]$ and plays an important role in several environmental processes and their consequent impacts. In terrestrial ecosystems, excess nitrogen causes soil acidification and loss of plant diversity [4], whereas in aquatic systems, it is responsible for eutrophication and algal blooms [5]. In the atmosphere, ammonia combines with other gases and causes the formation of fine particulates which are hazardous to human health [6]. Reactions with other pollutants like oxides of sulphur lead to the formation of fine particulates [7]. Reactions with primary pollutants, like oxides of nitrogen and sulphur as well as $\mathrm{HCl}$, cause the formation of ammonium ions $\left(\mathrm{NH}_{4}{ }^{+}\right)$. The ammonium ions consequently form the sulphates and nitrates, a major component of atmospheric aerosols [3, 8].

Large uncertainties exist in atmospheric emissions, chemistry, transport, and deposition of nitrogen compounds such as ammonia [9]. Agriculture sector is considered as the greatest source contributing to global atmospheric ammonia [10]. However, the influence of agriculture activities fluctuates greatly at smaller spatial scales. It has been estimated that about $57 \%$ of global atmospheric ammonia is released from livestock and crops [11], whereas the estimates during the year 2008 showed that about $49.3 \mathrm{Tg}$ was emitted in the atmosphere, out of which $81 \%$ was related to agriculture including agricultural soils, manure management, and agricultural burning. Vegetation fires have been attributed to 
the second most important source contributing to $16 \%$ of the total emissions [9]. Relative contribution and importance of these sources can vary on both local and regional scales.

Anthropogenic activities are the primary source for causing disruptions in the natural nitrogen cycle $[8,12]$ by enhancing ammonium deposition instead of nitrates. Mainly, the production of food and energy to meet the growing needs of the ever-increasing population leads to the disturbance of natural cycles of carbon and nitrogen. The deposition of ammonia and ammonium ions, either dry or wet, plays a significant part to impart adverse effects to sensitive ecosystems [12-14].

Ammonia regions with enhanced levels of fine particulate matter have been associated statistically with increased number of humans suffering pulmonary and cardiac diseases [15]. These fine particles also cause radiative force in the atmosphere [16] as well as reduce the visibility.

A single nitrogen atom (reactive nitrogen) while moving through the steps of its biogeochemical cycle can have a sequence of negative impacts [17]. These multiple effects can be observed in the atmosphere as well as in terrestrial, freshwater, and marine ecosystems with implications on human health as well and are termed as "Nitrogen Cascade".

Using observation from the tropospheric emission spectrometer (TES aboard Aura satellite), Beer et al. [18] gave the first account of boundary layer ammonia. The infrared atmospheric sounder interferometer (IASI), like TES, also retrieves ammonia in nadir viewing. For its retrieval, the IASI uses the spectrum which falls in the thermal infrared region. A clear picture of ammonia concentration over the globe has been obtained by the excellent coverage provided by the IASI instrument, along with simple measurements which are obtained by converting brightness temperature difference to total column measurements [10]. The TES has less spatial coverage compared to other satellitebased instruments like AIRS or IASI, but it has a higher spectral resolution of $0.1 \mathrm{per} \cdot \mathrm{cm}$. This property, in combination with a higher signal-to-noise ratio $(600: 1)$ of the TES instrument, provides sufficient sensitivity towards the boundary layer ammonia [9, 11]. An additional feature of the TES is the sun-synchronous orbit and has the ability to provide optimum conditions for high thermal contrast ultimately increasing the sensitivity towards ammonia [18]. Furthermore, high spectral resolution allows the selection of microwindows (spectral regions) with minimum interference from other atmospheric absorbers, thus reducing the systemic errors in the retrievals.

Despite all this, the knowledge about atmospheric abundances of ammonia and its spatial and seasonal variability is very limited. To account for variability in ammonia on spatial and temporal scales is mandatory in order to quantify its emissions, concentrations, and deposition [9]. It will also improve understanding about the fine particulate matter in the atmosphere.

The present paper describes the spatial and temporal distribution of ammonia over the South Asian region during the time period of 2004-2011. South Asia is home to $25 \%$ of the world's population. The continent is famous for its fertile plains hosting extensive agricultural activities.
Owing to the growing population and urbanization, South Asia is undergoing transformations in almost all the sectors of development. Agriculture sector is the backbone of this region. The primary objective was to explore the spatiotemporal patterns of ammonia columns over the study region and to identify the ammonia hot spots. This study also investigates the contribution of various ammonia sources and tries to interpret the role of agricultural activities and meteorological parameters in observed ammonia columns.

\section{Materials and Methods}

The data used in the present study were acquired from the tropospheric emission spectrometer (TES) aboard NASA's Aura satellite. The TES has the capacity to measure a wide variety of atmospheric pollutants such as $\mathrm{CO}$, ozone, water vapours, ammonia, and methanol $[11,19,20]$, along with the standard products that are retrieved operationally.

The instrument has the capability to measure in both limb (side view) and nadir (straight down) viewing. It has an altitude coverage of 0 to $34 \mathrm{~km}$ with higher spectral resolution from 5.3 to $15.4 \mu \mathrm{m}$. It scans over a swath of $5.3 \times 8.5 \mathrm{~km}$ with rectangular pixel size of $0.53 \times 5.3 \mathrm{~km}$ and allows for the detection of localized sources. The satellite revolves in a sun-synchronous orbit at an altitude of about $705 \mathrm{~km}$ and possesses a good signal-to-noise ratio of $600: 1$ [11]. One of the species that can additionally be retrieved is ammonia [9]. For the current study, level 2 data were obtained on a monthly basis from September 2004 to December 2011 and were subjected to further processing.

The satellite data in raw form were subjected to various processing steps as shown in the methodology flow chart (Figure 1). The data were available with global coverage; however, ammonia total columns were extracted over the South Asian region by using ArcGIS tools. Finally, monthly mean maps were generated over South Asia and each country and various regions like the Indo-Gangetic Plain and provinces of Pakistan. Maps were generated using ArcMap 10.3.1. These were monthly maps with extractions over South Asia, provinces of Pakistan, and IGP regions. Furthermore, seasonal mean for Rabi and Kharif cropping periods in addition to annual and long-year maps were generated. Spatiotemporal analysis was performed, and the results are represented graphically and statistically in the following sections.

The fertilizer use data for various months and seasons were obtained from the National Fertilizer Development Centre, Pakistan. These data were linked to the emissions of ammonia in Pakistan. The emissions were also correlated with temperature and precipitation trends in the region.

\section{Results and Discussion}

3.1. Spatial Distribution of Ammonia across South Asia. South Asia is famous for its fertile plains hosting extensive agricultural activities. Owing to the growing population and urbanization, South Asia is undergoing transformations in almost all the sectors of development. Spatial distribution of 


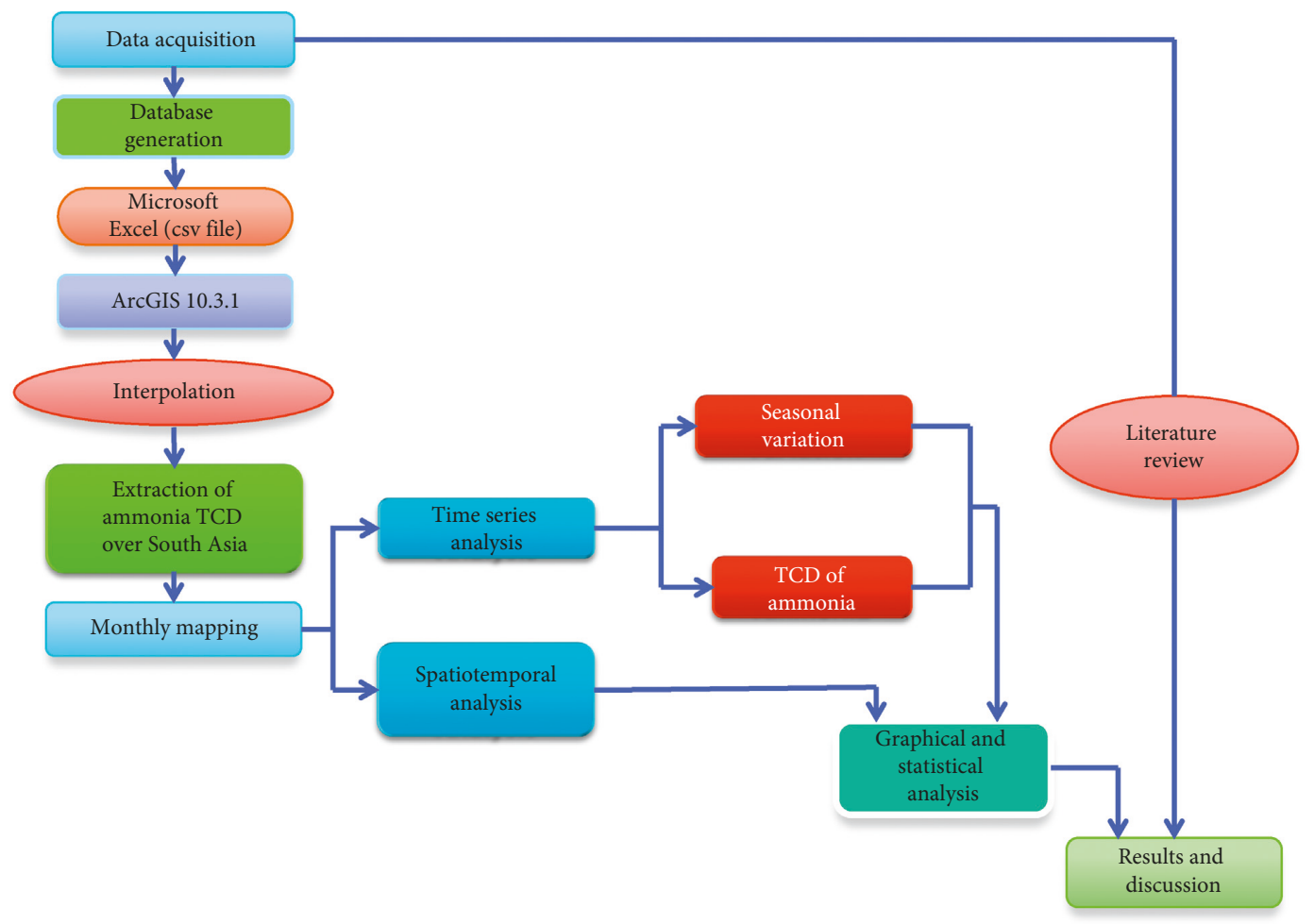

FIgURE 1: Methodology flow chart exhibiting the datasets, procedure, and tools used in this study.

ammonia column densities across South Asia averaged over the period of year 2004-2011 is presented in Figure 2. It is evident that the ammonia columns are higher in the area marked by red polygons. The area marked by red polygons basically consists of plains of the Indus and Ganges river basins. This area is generally known as the Indo-Gangetic Plain (IGP). The plain extends from the Arabian Sea to the Bay of Bengal and from the Himalayan foothills to the Indian peninsula. The region covers a total of $21 \%$ of the geographic area of India, $14 \%$ of the territory of Nepal, $24 \%$ of the area of Pakistan, and $100 \%$ of the area of Bangladesh. The IGP region is prominent as the world's largest food basket and hosts extensive agriculture activities. The main causes of $\mathrm{NH} 3$ emissions are the production and use of ammoniabased fertilizers [6]. Enhanced $\mathrm{NH}_{3}$ columns over the IGP region are in compliance with the speculated ammonia emissions of the agriculture sector $[6,12]$.

3.2. Temporal Analysis. Temporal analysis of ammonia columns from South Asia is presented in Figure 3. Monthly means of ammonia columns retrieved from TES observations over South Asia during the time period of September 2004 to September 2011 were used. An overall relative change of $6 \%$ is observed during the study period. Time series has exhibited certain seasonality in the observed ammonia columns with maximum during the summer months. The values have been observed to rise during the months of June-July and December every year, although the anomalies do exist sometimes. This can be attributed to fertilizer intake for rice crop in summer and wheat crops during the months of December-January.
3.3. Trends in Ammonia Columns over IGP Regions. Climate in the IGP ranges from warm temperate to subtropical. The region is characterized by winter season which is cool and dry, while summer that is warm and humid. The IGP has been subdivided into six major subregions shown in Figure 4 depending upon the physiography and bioclimate [21]. Trans-Gangetic Plain (transects 1A and 1B) occupy large areas of Pakistan and Punjab and Haryana (transect 2) in India. Transects 3 and 4 comprise areas in Uttar Pradesh, Bihar, and Nepal. Lower parts of the Gangetic Plain in West Bengal, India, and parts of Bangladesh constitute transect 5 [22].

It has been observed that the general trend in ammonia column densities for the regions $1 \mathrm{~A}, 1 \mathrm{~B}, 2$, and 3 is more or less the same with peaks observed during June-July. While for the regions 4 and 5, the trend is different from the others with peaks during the months of January and February, respectively. The time series for all these regions has been depicted in Figure 5. This dissimilarity can be attributed due to difference in crop seasons across the Indo-Gangetic Plain.

3.4. Analysis of Crop Seasons. Two distinct crop seasons exist in the IGP: Rabi and Kharif. The ammonia columns show prominent difference during these two seasons. This has been depicted by the time series presented in Figure 6 .

It shows that the trend of ammonia columns increases during Kharif months in the IGP with the exception of the last two regions (Zone 4 and Zone 5) with a few exceptions (IGP-3 in 2005 and IGP-5 in 2010). Further analyses revealed that IGP subregions $1 \mathrm{a}, 1 \mathrm{~b}, 2$, and 3 host almost similar cropping seasons (with an offset of about few days 


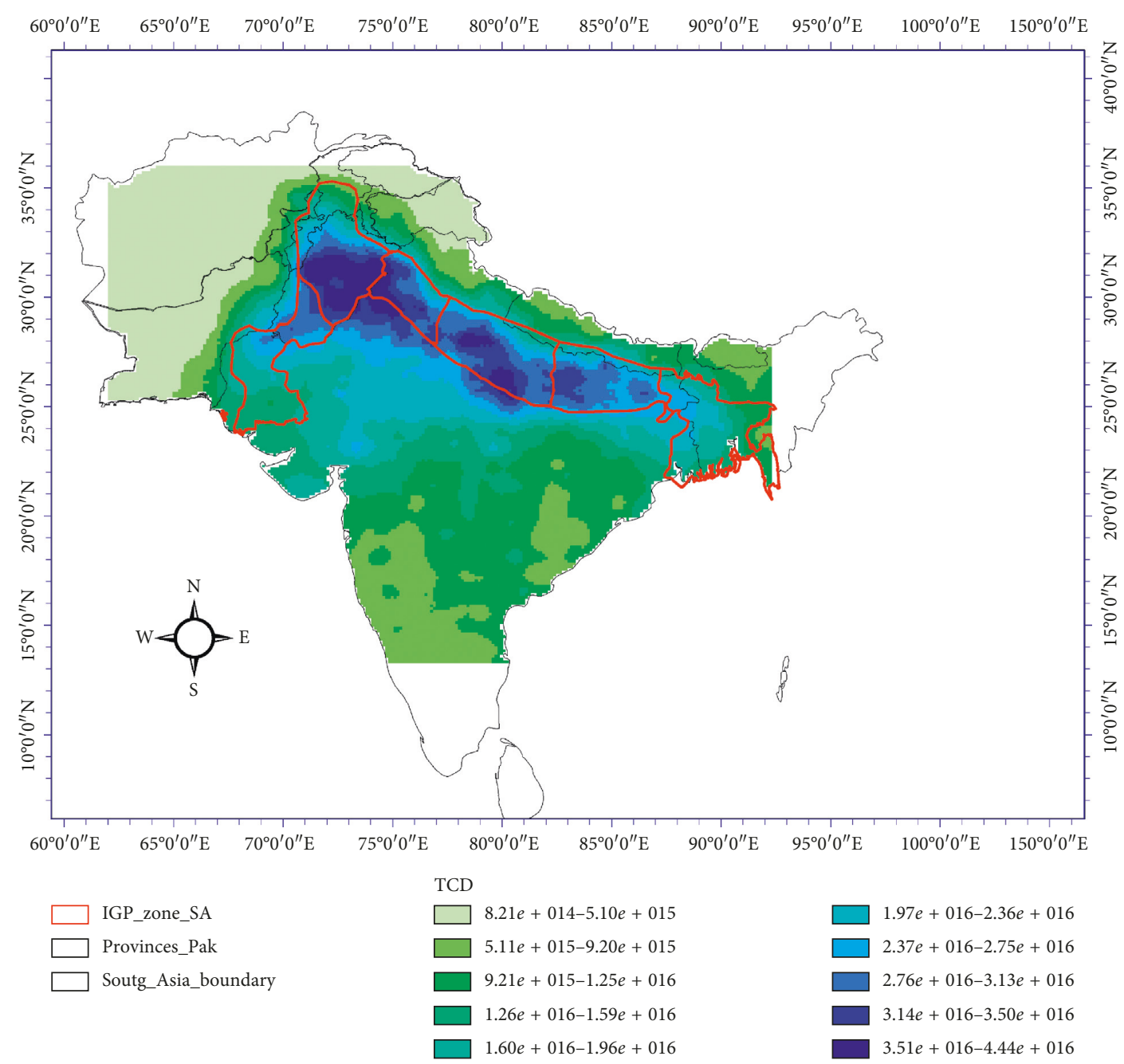

Figure 2: Average map of $\mathrm{NH}_{3}$ columns (molecules $/ \mathrm{cm}^{2}$ ) for years 2004-2011 over South Asia. Red polygons indicate the subregions of the Indo-Gangetic Plain (IGP).

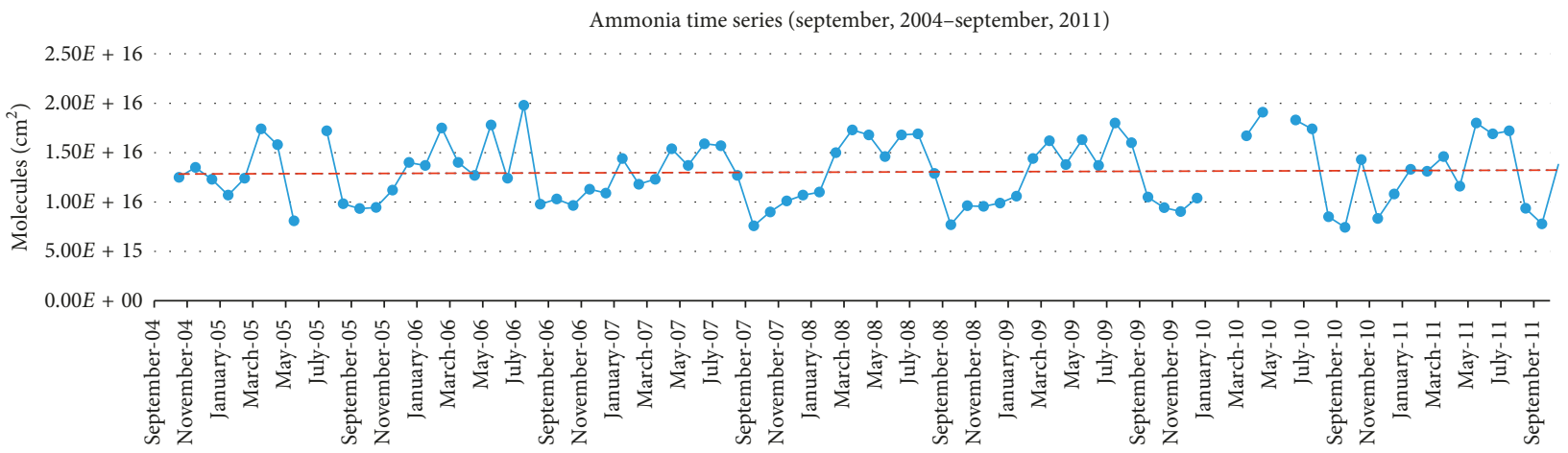

Figure 3: Time series of ammonia columns $\left(\right.$ molecules $/ \mathrm{cm}^{2}$ ) over South Asia showing high peak over the month of July and a slight rise from 2004 to 2011.

from east to west), climate, and precipitation patterns as compared to subregions 4 and 5 . The precipitation pattern as observed in IGP subregions 2 to 5 (India and Bangladesh) has been depicted in Figure 7 [23].

It exhibited maximum precipitation during Kharif season in IGP subregions 4 and 5 as compared to subregions
2 and 3. It can be speculated that due to heavy rains with consequent stagnant water and humid conditions during Kharif season, comparatively limited agriculture activities are happening as compared with other subregions in the IGP. It was further supported by the SPOT vegetation data presented in Figure 8. It depicts the level of agriculture 

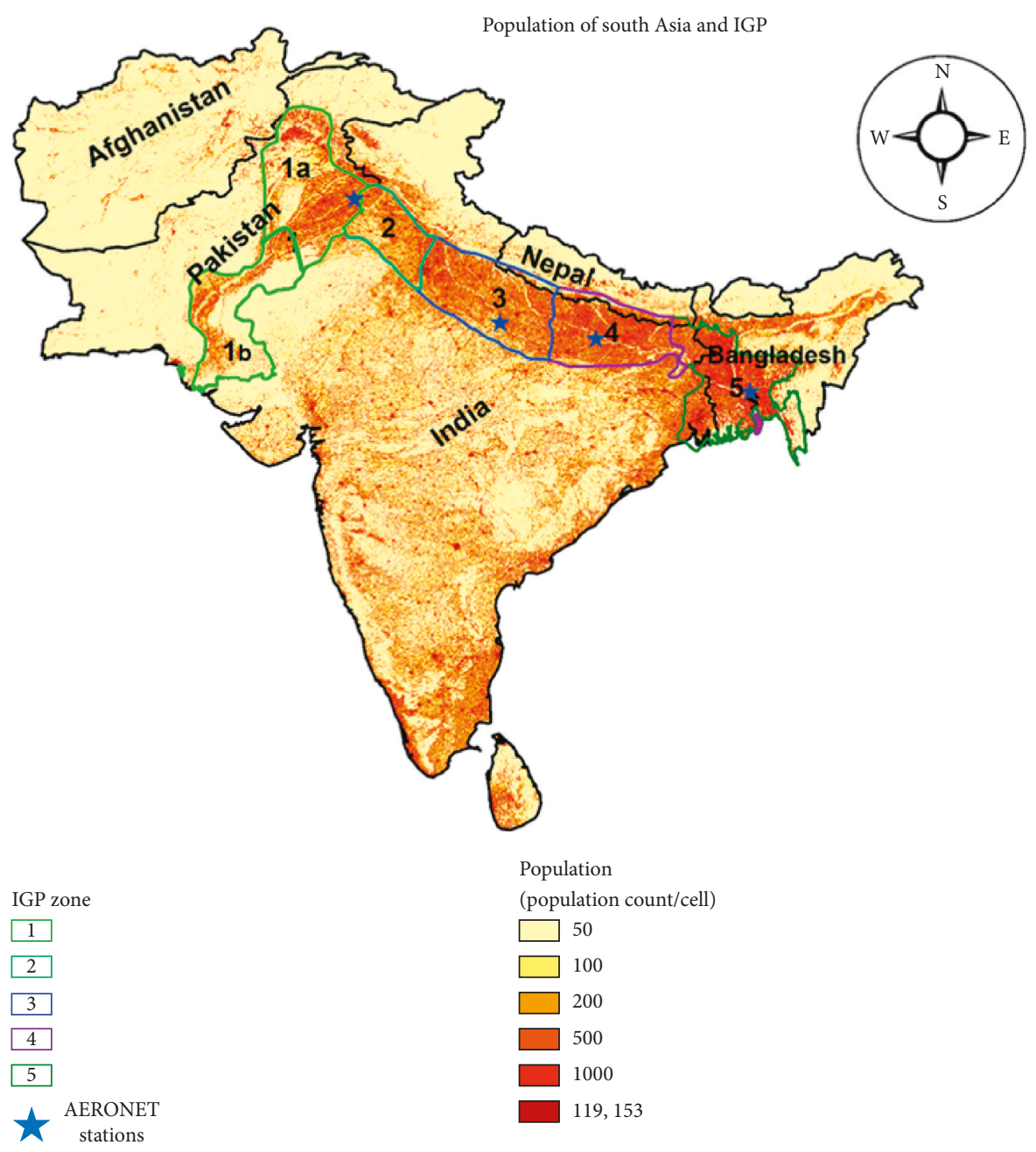

FIGURE 4: Six major subregions of the IGP based on population density, adopted from Khokhar and Yasmin, 2018.

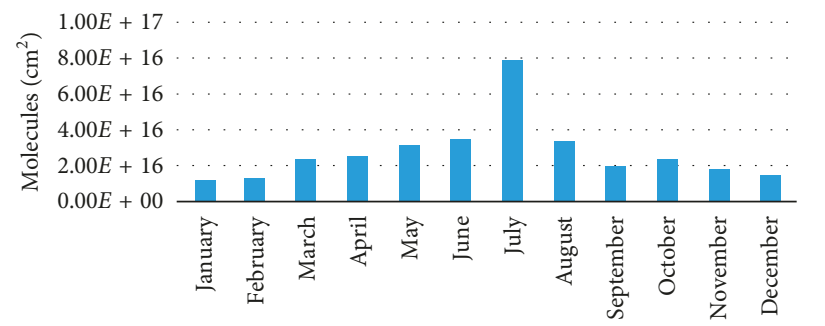

(a)

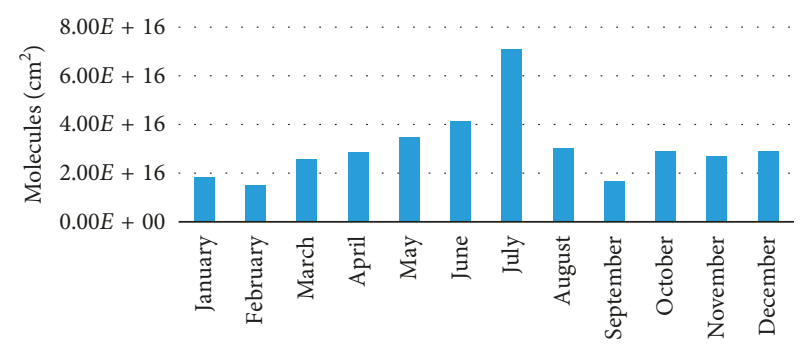

(c)

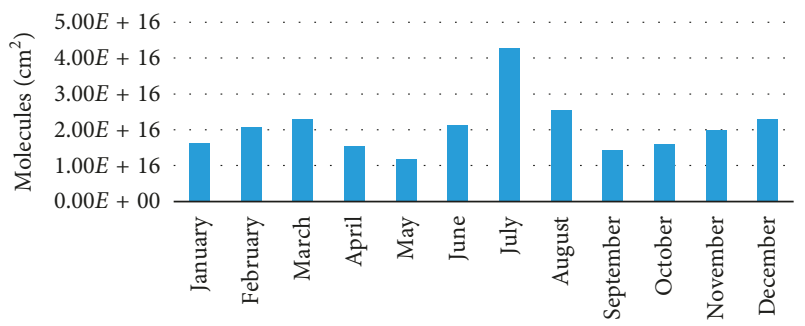

(b)

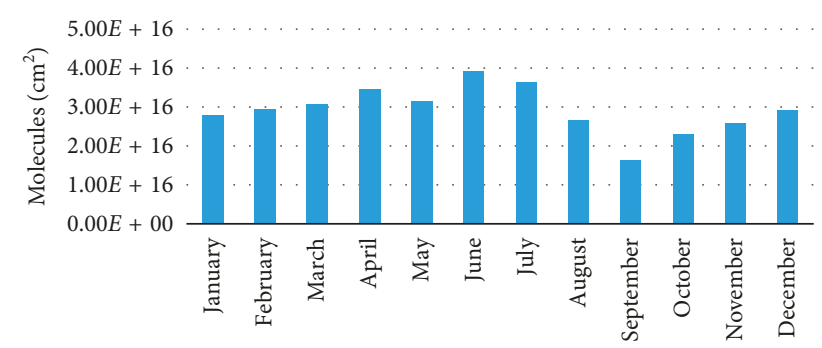

(d)

FIGURE 5: Continued. 


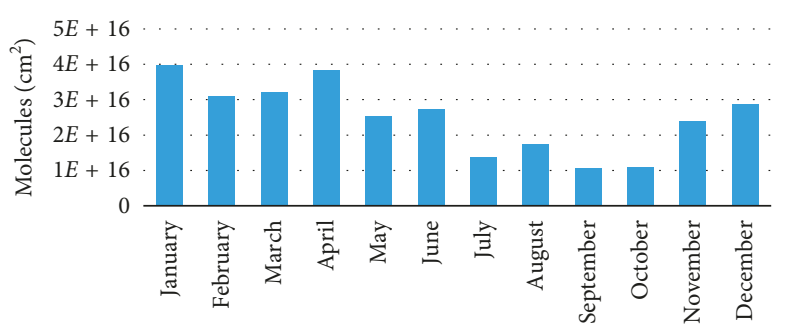

(e)

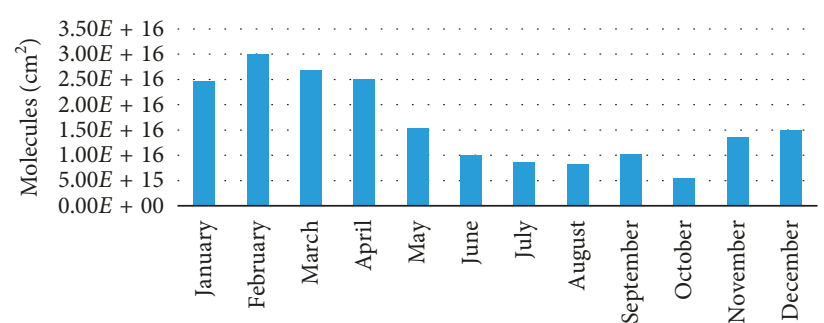

(f)

FIGURE 5: Seasonal variations of ammonia columns (molecules $/ \mathrm{cm}^{2}$ ) over different regions of the study area. The trend over IGP-4 and IGP5 shows discrepancy from the observed normal for the other regions. (a) IGP-1A. (b) IGP-1B. (c) IGP-2. (d) IGP-3. (e) IGP-4. (f) IGP-5.

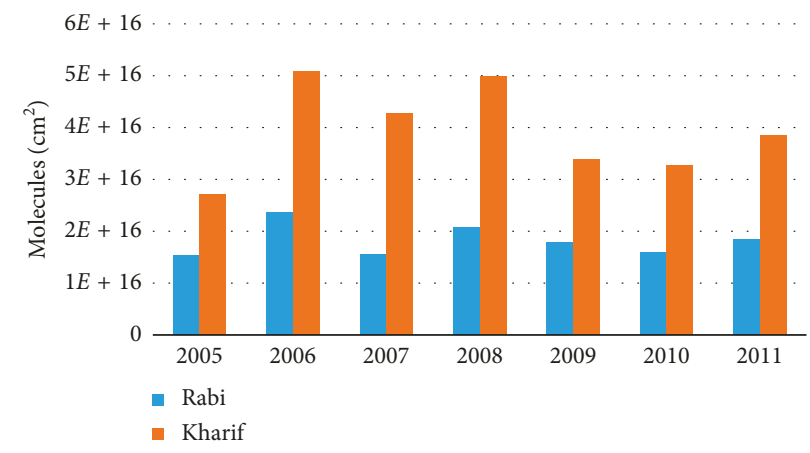

(a)

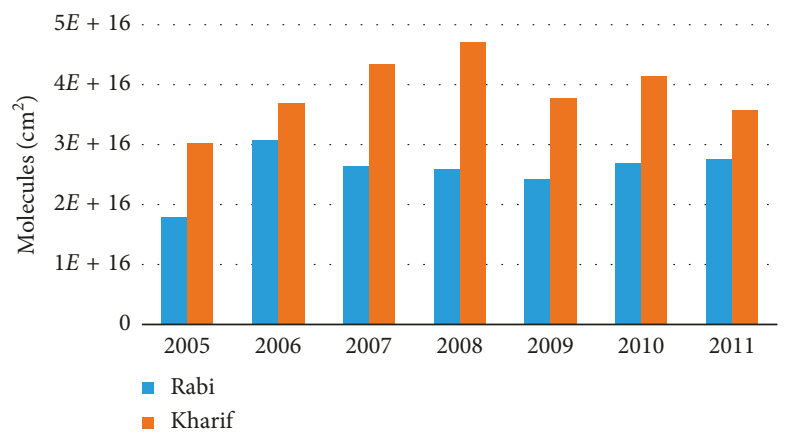

(c)

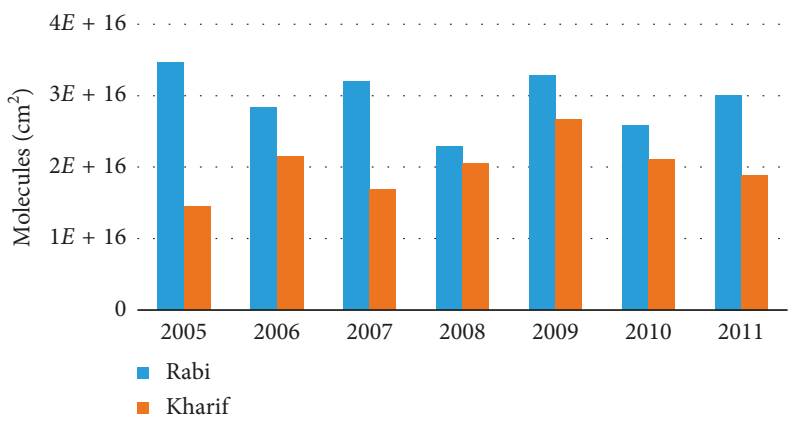

(e)

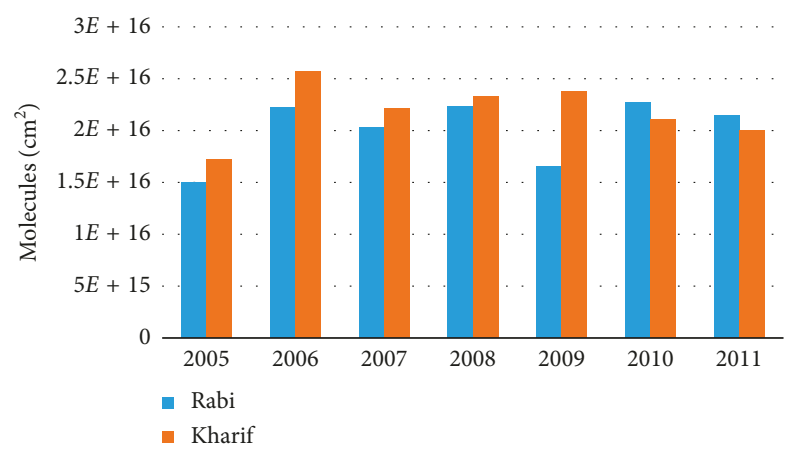

(b)

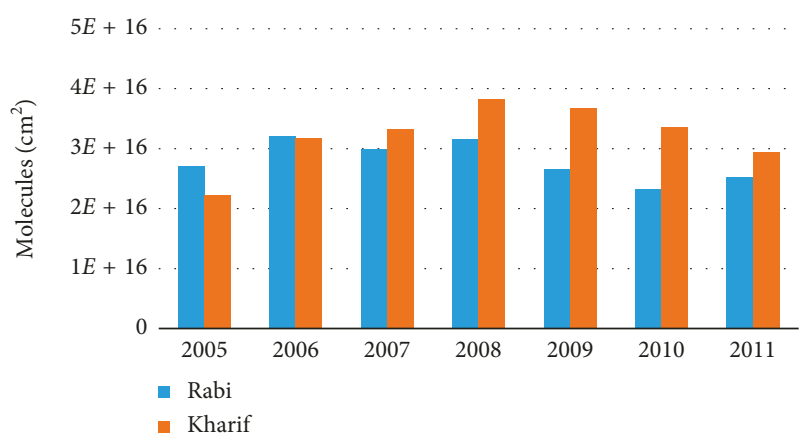

(d)

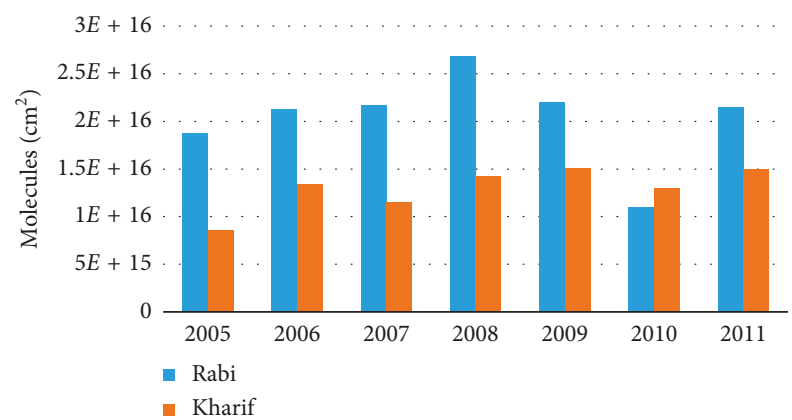

(f)

FIGURe 6: Rabi versus Kharif columns (molecules $/ \mathrm{cm}^{2}$ ) for the IGP regions plotted side by side shows that Kharif emissions are generally higher compared to Rabi emissions for the first four regions and are lower in case of IGP-4 and IGP-5. (a) IGP-1A. (b) IGP-1B. (c) IGP-2. (d) IGP-3. (e) IGP-4. (f) IGP-5.

activities (no/low agriculture: pink; areas with medium agriculture: yellow; areas with extensive agriculture: green) within the study region for both Kharif (Figure 8(a)) and
Rabi (Figure 8(b)) seasons in the IGP. It is evident from Figure 8 that subregions 4 and 5 host very low agriculture activities during Kharif season as compared to other regions 

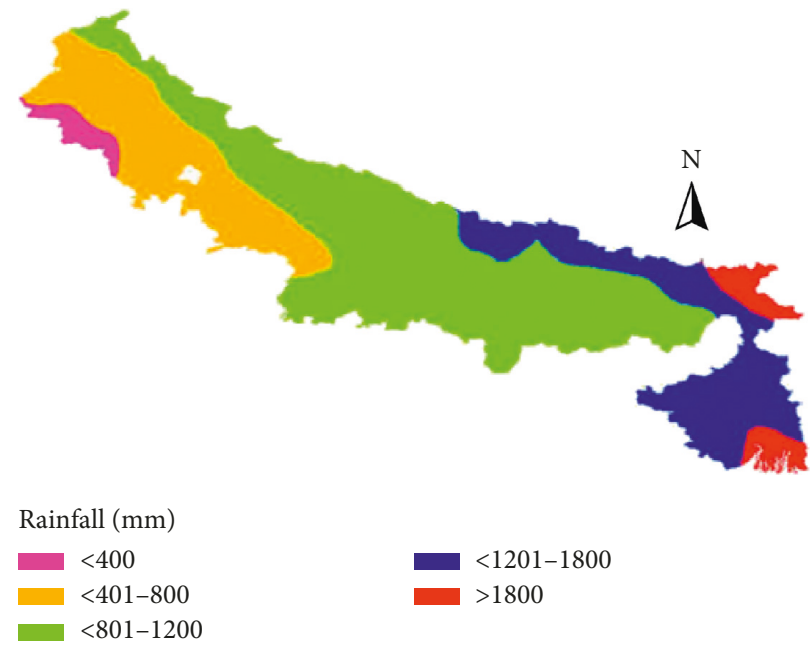

FIGURE 7: Precipitation over the IGP: the colours depict the level of monsoon rains (Kharif) over the Indian and Bangladeshi parts of the IGP as adopted from Koshal (2014).

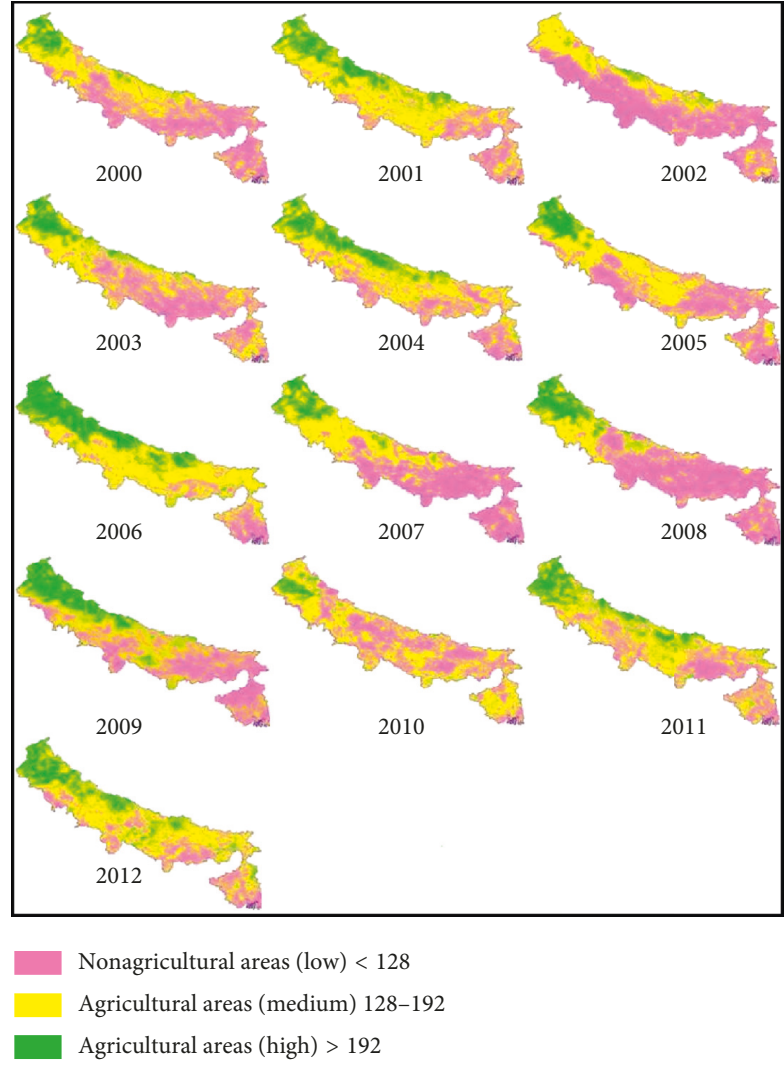

(a)

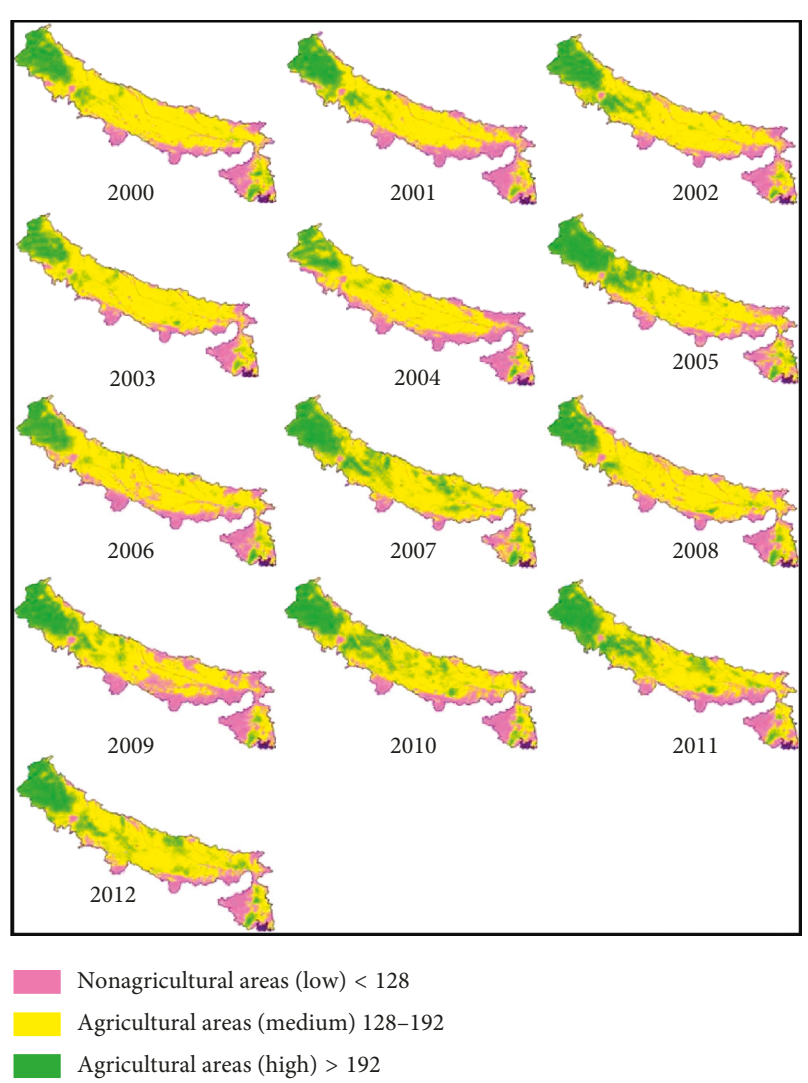

(b)

Figure 8: SPOT vegetation over the IGP for Kharif (a) and Rabi (b) as adopted from Koshal, 2014.

of the IGP. The corresponding decline in ammonia emissions during these months as depicted in Figure 6 for these regions validates the hypothesis adopted for this study that ammonia emissions in this region predominantly come from agriculture.

It justifies the different trends obtained for subregions 4 and 5. Also, there were some exceptions observed for subregion 3 during the year 2005. It was further investigated by comparing vegetation during both seasons in the year 2005. It revealed that more agriculture activity was carried out in Rabi in 2005 than that in Kharif season in subregion 3. Similarly, during the year 2010, in subregion 5, anomalous high vegetation was observed during the Kharif season than that during Rabi season as shown in Figure 8. Reason behind 


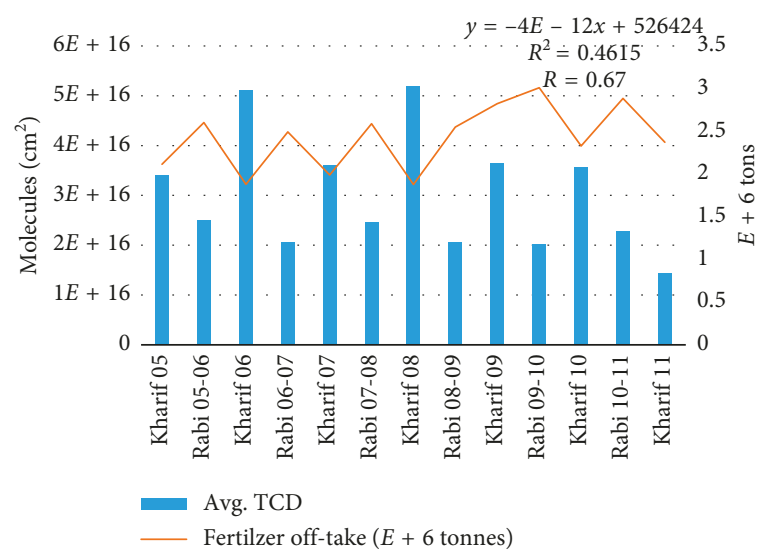

(a)

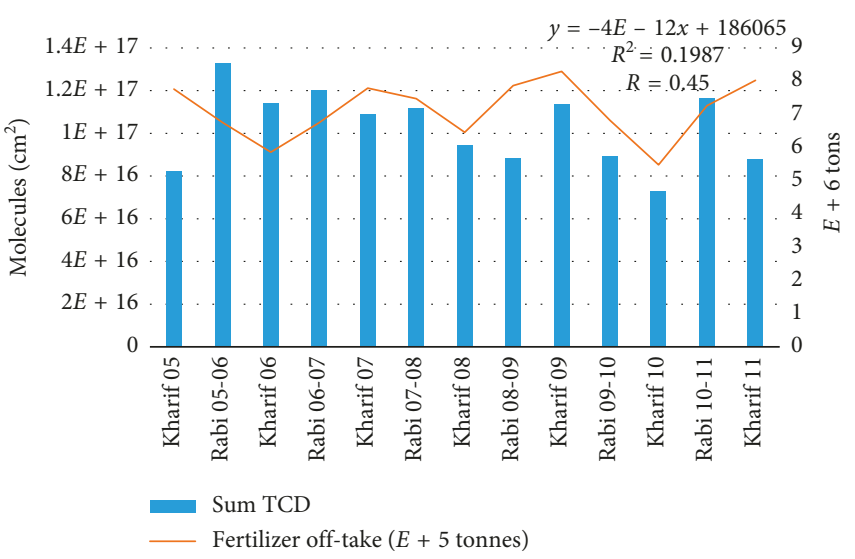

(b)

FIgUre 9: Total column density of ammonia (molecules $/ \mathrm{cm}^{2}$ ) versus total fertilizer offtake (tons) as obtained from the National Fertilizer Development Centre, Pakistan, for the provinces majorly falling under the IGP. (a) Punjab. (b) Sindh.

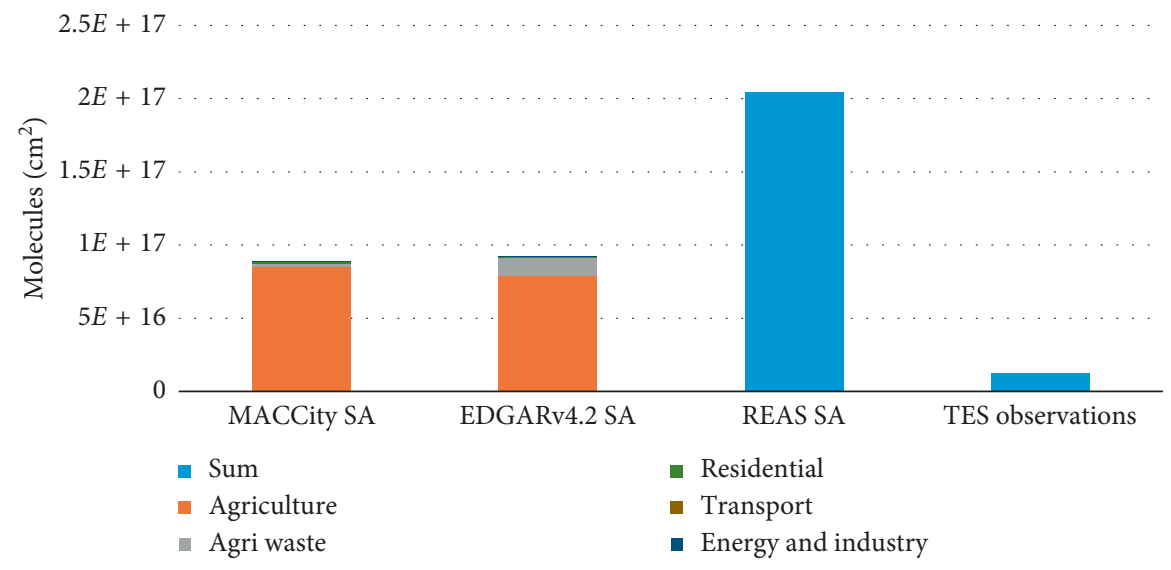

(a)

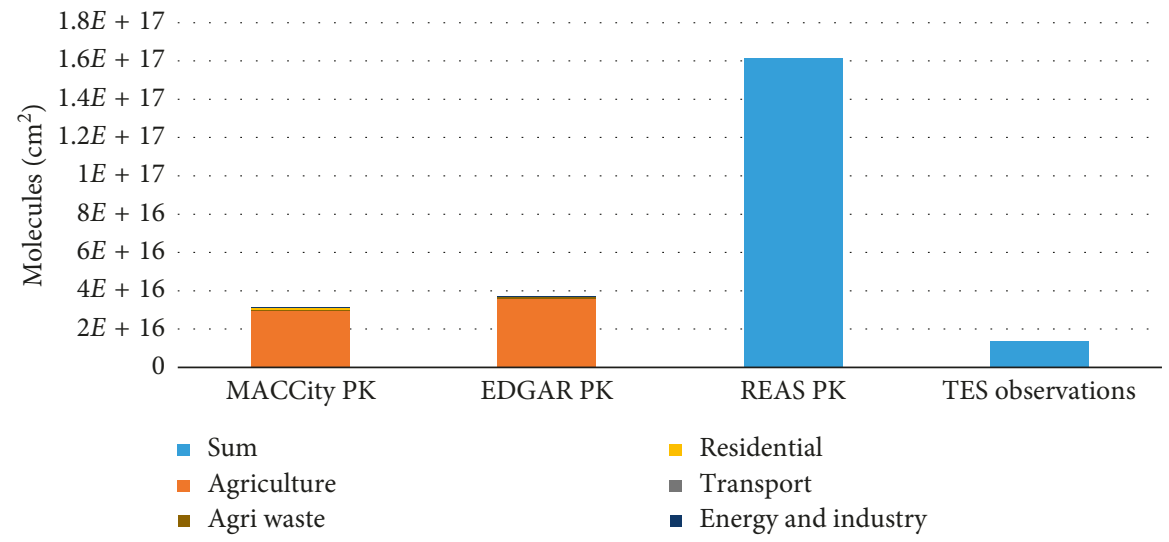

(b)

Figure 10: Continued. 


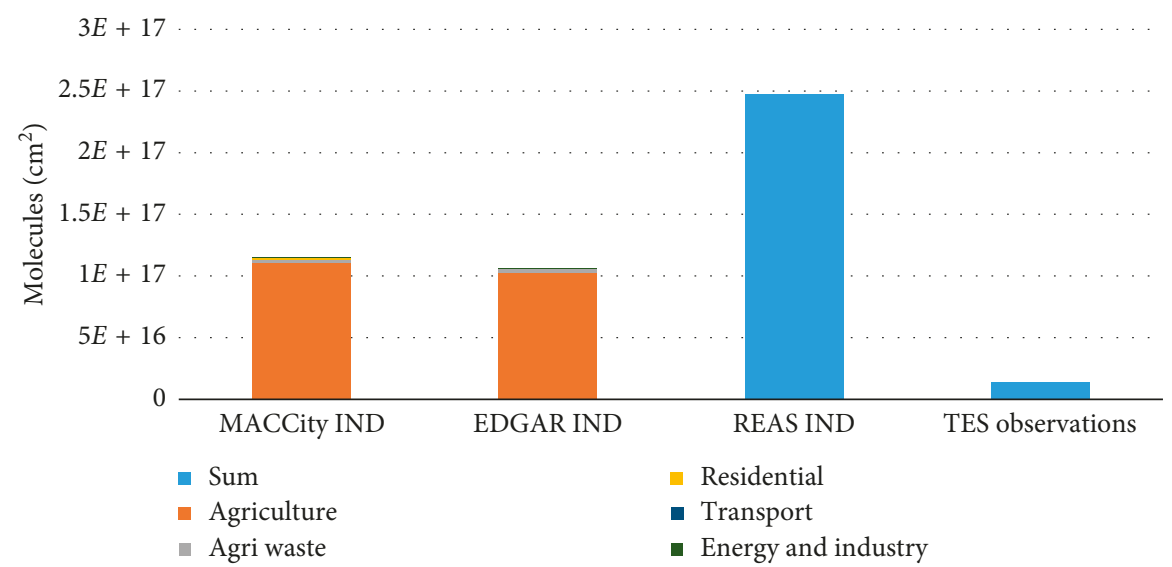

(c)

FIGURE 10: Calculated values for ammonia column densities (molecules $/ \mathrm{cm}^{2}$ ) from the regional and global inventories (MACCity, EDGAR, and REAS) against observed values from the TES instrument on the Aura satellite over (a) South Asia, (b) Pakistan, and (c) India.

such an anomaly is not clear yet; however, it can be attributed to relatively less rains during 2010 in subregion 5.

\section{Fertilizer Offtake and Regional Ammonia Columns}

One of the major factors involved in ammonia emissions is the use of ammonia-based fertilizers [24]. The data obtained from the National Fertilizer Development Centre, Pakistan, have been statistically analysed over the agriculture-intensive areas of Punjab and Sindh provinces (subregions 1a and $1 \mathrm{~b}$, respectively). The comparison between fertilizer intake and atmospheric ammonia columns is depicted in Figure 9.

These illustrations show that ammonia columns and fertilizer offtake are reasonably correlated. At times, the $\mathrm{NH}_{3}$ column density happens to increase with increasing fertilizers, while the reverse also occurs at other points. It is not possible to look for exact correlations between these two datasets as they are not harmonious in space and time. First, the satellite observations from a single point on the globe are taken every sixteen days which is not consistent with the fertilizer offtake data obtained from the National Fertilizer Development Centre. Furthermore, ammonia has a short life span of about 2-10 days [2] which makes it difficult to be traced by TES observations with such high precision levels.

4.1. Monitored vs. Calculated Ammonia Columns. There has been observed a wide difference between the amounts of ammonia column densities as measured by TES and that of calculated using the data from the global emission inventories. The satellite largely underestimates the ammonia emissions. The most probable reason for this difference is that ammonia has a lifetime of about 5 days, while the satellite observes it after every 16 days, leaving majority of the emissions undetected. REAS observations are overestimated as compared to MACCity and EDGAR v4.0 exhibiting relatively less difference with TES observations.
REAS does not give any source contribution for the emissions and just gives an idea of total ammonia emissions. This might have caused ambiguities in its results. Furthermore, REAS is a regional inventory, and all the emission inventories differ from each other. For instance, EDGAR overestimates the emissions from agriculture wastes. The comparison of these inventories with the satellite has been shown in Figure 10 for (a) South Asia, (b) Pakistan, and (c) India.

\section{Conclusions}

Extensive agricultural activity with more use of synthetic fertilizers is one of the pronounced causes of ammonia emissions in the atmosphere. The time series generated for the various regions of the study area clearly depicted that the ammonia column density is higher over the agricultureintensive areas of South Asia, commonly termed as the IndoGangetic Plain. The results show a $6 \%$ in overall ammonia columns over the study region with pronounced seasonality, which is maximum during the month of July every year, with few exceptions over some regions (IGP-4, 5). Analyses for different crop seasons showed higher Kharif emissions than Rabi emissions for some agricultural regions (IGP-1,2,3) while they were opposite for the others (IGP-4,5) owing to varying trends in agricultural practices, precipitation, and humidity, which account for ammonia volatilization. The observed ammonia columns from the TES-Aura have also been compared with global emission inventories. The comparison has clearly indicated that satellite observations are underestimated as compared to ammonia emissions given by global emission inventories. It can be explained by the fact that ammonia owing to a short lifetime of few days is not fully observed by the TES observations with a revisit time of 16 days. Also, satellite observations averaged over larger areas due to coarse spatial resolution. Furthermore, satellite observations are largely impacted by the aerosol- and cloudshielding effect $[25,26]$. The correlation with fertilizer offtake data obtained from the National Fertilizer Development 
Centre, Pakistan, yielded moderately reasonable correlation with satellite ammonia columns over the agriculture-intensive provinces of Punjab and Sindh in Pakistan. The results have provided with a substantial evidence for ammonia emissions related to agricultural activity in the study area for the observed time period. However, there is strong need to validate satellite observation of ammonia columns with ground-based ammonia measurements on a regular basis.

\section{Data Availability}

The data used to support the findings of this study are available from the corresponding author upon request.

\section{Conflicts of Interest}

The authors declare that there are no conflicts of interest regarding the publication of this paper.

\section{Acknowledgments}

This work was carried out as postgraduate research work at the NUST, Islamabad, Pakistan. The authors gratefully acknowledge the TES L2 data product, courtesy of the online Data Pool at the Atmospheric Science Data Center at NASA and the National Fertilizer Development Centre, Islamabad, Pakistan. The funding for this research work was provided by the NUST postgraduate research grant.

\section{References}

[1] N. Anderson, R. Strader, and C. Davidson, “Airborne reduced nitrogen: ammonia emissions from agriculture and other sources," Environment International, vol. 29, no. 2-3, pp. 277-286, 2003.

[2] P. Hobbs, Introduction to Atmospheric Chemistry, Cambridge University Press, Cambridge, UK, 2006.

[3] R. W. Pinder, A. B. Gilliland, and R. L. Dennis, "Environmental impact of atmospheric $\mathrm{NH}_{3}$ emissions under present and future conditions in the eastern United States," Geophysical Research Letters, vol. 35, no. 12, 2008.

[4] J. G. M. Roelofs, A. J. Kempers, A. L. F. M. Houdijk, and J. Jansen, "The effect of air-borne ammonium sulphate onPinus nigra var. maritima in the Netherlands," Plant and Soil, vol. 84, no. 1, pp. 45-56, 1985.

[5] R. Bobbink, D. Boxman, E. Fremstad, G. Heil, A. Houdijk, and J. Roelofs, "Critical loads for nitrogen eutrophication of terrestrial and wetland ecosystems based upon changes in vegetation and fauna [alpine heathlands, deposition]," Critical Loads for Nitrogen, vol. 41, pp. 111-159, 1992.

[6] S. N. Behera, M. Sharma, V. P. Aneja, and R. Balasubramanian, "Ammonia in the atmosphere: a review on emission sources, atmospheric chemistry and deposition on terrestrial bodies," Environmental Science and Pollution Research, vol. 20, no. 11, pp. 8092-8131, 2013.

[7] Y. Zhou, Y. Zhang, D. Tian, and Y. Mu, "Impact of dicyandiamide on emissions of nitrous oxide, nitric oxide and ammonia from agricultural field in the north China plain," Journal of Environmental Sciences, vol. 40, pp. 20-27, 2015.
[8] J. H. Seinfeld, "ES\&T books: atmospheric chemistry and physics of air pollution," Environmental Science \& Technology, vol. 20, no. 9, p. 863, 1986.

[9] M. Van Damme, L. Clarisse, C. L. Heald et al., "Global distributions, time series and error characterization of atmospheric ammonia $\left(\mathrm{NH}_{3}\right)$ from IASI satellite observations," Atmospheric Chemistry and Physics, vol. 14, no. 6, pp. 29052922, 2014.

[10] A. H. W. Beusen, A. F. Bouwman, P. S. C. Heuberger, G. Van Drecht, and K. W. Van Der Hoek, "Bottom-up uncertainty estimates of global ammonia emissions from global agricultural production systems," Atmospheric Environment, vol. 42, no. 24, pp. 6067-6077, 2008.

[11] M. A. Sutton, S. Reis, S. N. Riddick et al., "Towards a climatedependent paradigm of ammonia emission and deposition," Philosophical Transactions of the Royal Society B: Biological Sciences, vol. 368, no. 1621, article 20130166, 2013.

[12] W. A. H. Asman, M. A. Sutton, and J. K. Schjorring, "Ammonia: emission, atmospheric transport and deposition," New Phytologist, vol. 139, no. 1, pp. 27-48, 1998.

[13] K. B. Beem, S. Raja, F. M. Schwandner et al., "Deposition of reactive nitrogen during the rocky mountain airborne nitrogen and sulfur (RoMANS) study," Environmental Pollution, vol. 158, no. 3, pp. 862-872, 2010.

[14] F. Paulot, D. J. Jacob, and D. K. Henze, "Sources and processes contributing to nitrogen deposition: an adjoint model analysis applied to biodiversity hotspots worldwide," Environmental Science \& Technology, vol. 47, no. 7, pp. 3226-3233, 2013.

[15] C. A. Pope III, "Epidemiology of fine particulate air pollution and human health: biologic mechanisms and who's at risk?," Environmental Health Perspectives, vol. 108, no. 4, pp. 713$723,2000$.

[16] J. P. Martin and H. D. Chapman, "Volatilization of ammonia from surface-fertilized soils," Soil Science, vol. 71, no. 1, pp. 25-34, 1951.

[17] J.-W. Erisman, A. W. M. Vermetten, W. A. H. Asman, A. Waijers-Ijpelaan, and J. Slanina, "Vertical distribution of gases and aerosols: the behaviour of ammonia and related components in the lower atmosphere," Atmospheric Environment (1967), vol. 22, no. 6, pp. 1153-1160, 1988.

[18] R. Beer, M. W. Shephard, S. S. Kulawik et al., "First satellite observations of lower tropospheric ammonia and methanol," Geophysical Research Letters, vol. 35, no. 9, 2008.

[19] L. Clarisse, C. Clerbaux, F. Dentener, D. Hurtmans, and P.-F. Coheur, "Global ammonia distribution derived from infrared satellite observations," Nature Geoscience, vol. 2, no. 7, pp. 479-483, 2009.

[20] R. Beer, "TES on the aura mission: scientific objectives, measurements, and analysis overview," IEEE Transactions on Geoscience and Remote Sensing, vol. 44, no. 5, pp. 1102-1105, 2006.

[21] M. W. Shephard, K. E. Cady-Pereira, M. Luo et al., "TES ammonia retrieval strategy and global observations of the spatial and seasonal variability of ammonia," Atmospheric Chemistry and Physics, vol. 11, no. 20, pp. 10743-10763, 2011.

[22] L. Clarisse, M. W. Shephard, F. Dentener et al., "Satellite monitoring of ammonia: a case study of the San Joaquin valley," Journal of Geophysical Research: Atmospheres, vol. 115, no. D13, 2010.

[23] A. K. Koshal, "Changing current scenario of rice-wheat system in Indo-Gangetic plain region of India," International Journal of Scientific and Research Publications, vol. 4, no. 3, pp. 1-13, 2014. 
[24] H. M. Worden, M. N. Deeter, C. Frankenberg et al., "Decadal record of satellite carbon monoxide observations," Atmospheric Chemistry and Physics, vol. 13, no. 2, pp. 837-850, 2013.

[25] R. S. Narang and S. M. Virmani, "Rice-wheat cropping systems of the Indo-Gangetic plain of India," No. REP-8944, CIMMYT, Texcoco, Mexico, 2001.

[26] H. Pathak, J. K. Ladha, P. K. Aggarwal et al., "Trends of climatic potential and on-farm yields of rice and wheat in the Indo-Gangetic plains," Field Crops Research, vol. 80, no. 3, pp. 223-234, 2003. 

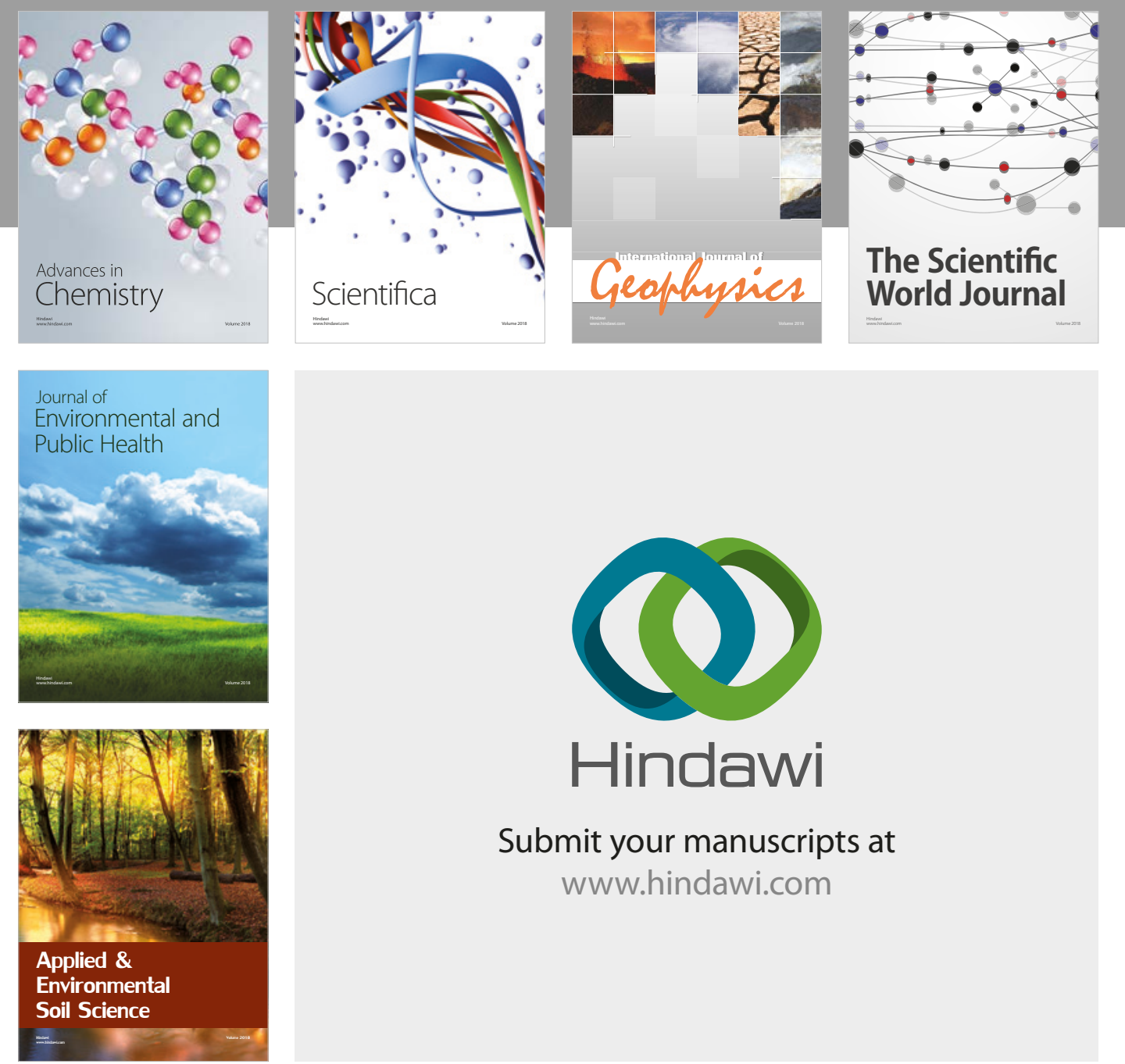

The Scientific

\section{World Journal}
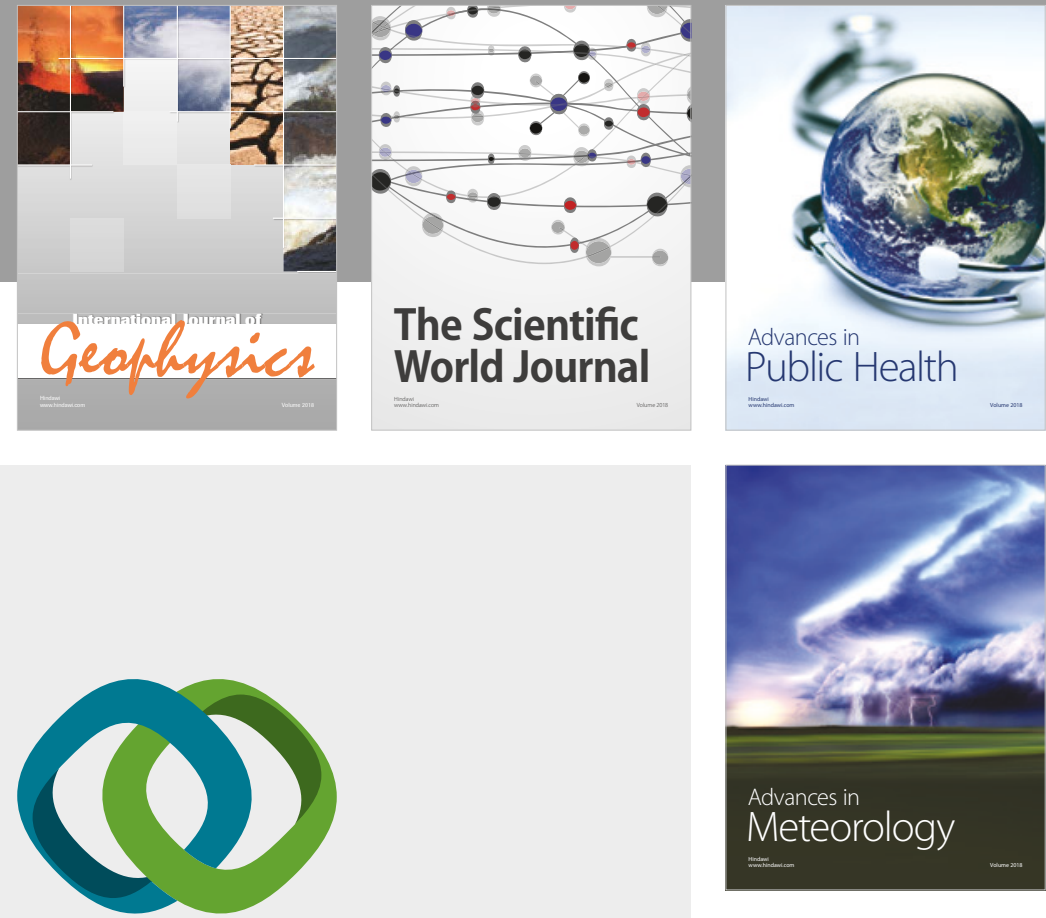

Advan

Public Health

\section{Hindawi}

Submit your manuscripts at

www.hindawi.com
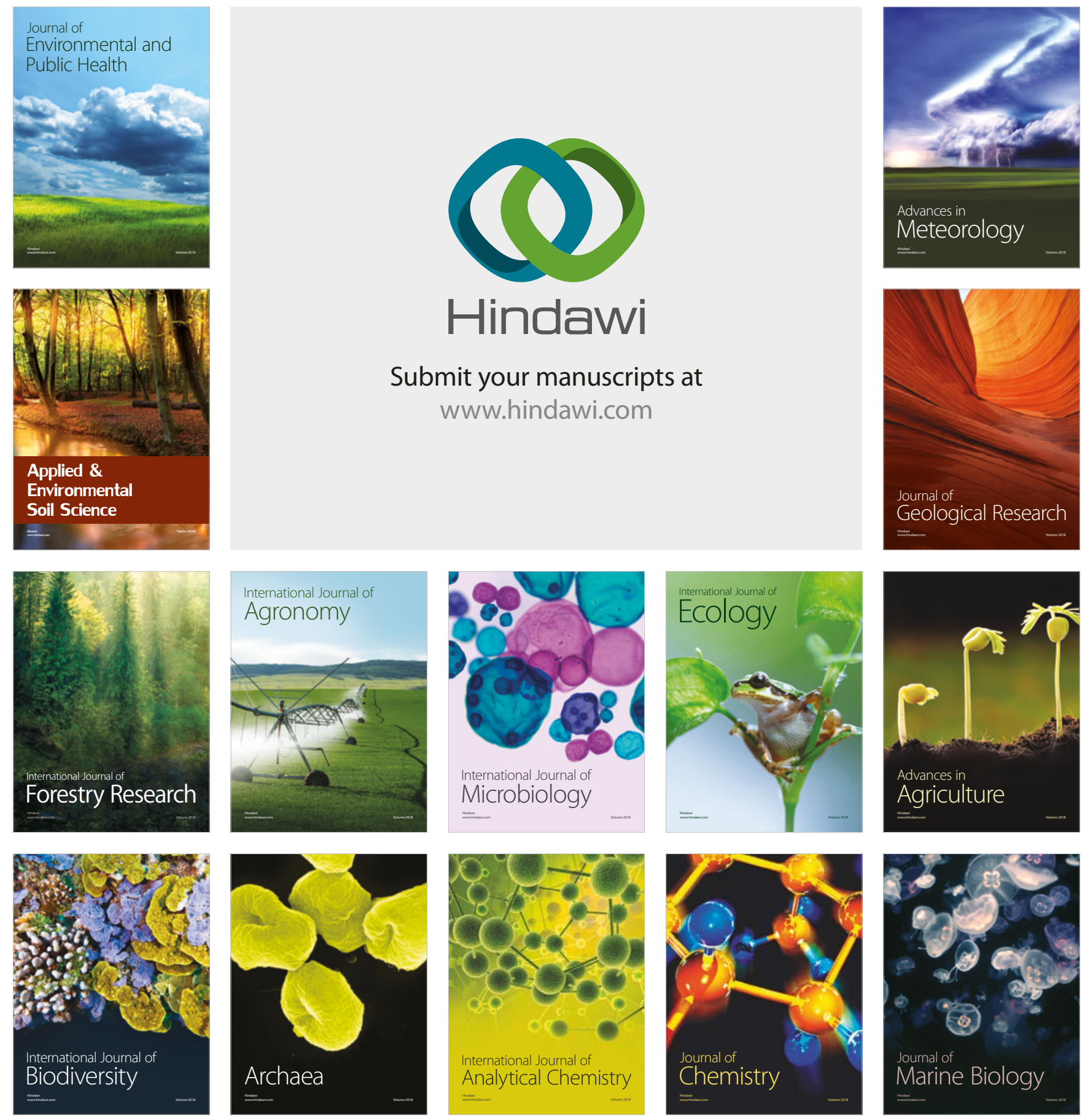